UDC 621.382 .822

\title{
Fabrication of nanoporous alumina by two-step anodization and studyof their structural properties
}

\author{
Alpysbayeva B.E. ${ }^{1,2}$, Abdullin Kh.A. ${ }^{1}$, Sazonov A.Yu. ${ }^{3}$, Kalkozova Zh.K. ${ }^{1}$ \\ ${ }^{I}$ Al-Farabi Kazakh National University, NNLOT, al-Farabi71, 050040 Almaty, Kazakhstan \\ ${ }^{2}$ Al-Farabi Kazakh National University, Laboratory of Engineering Profile, al-Farabi71, 050040 Almaty, Kazakhstan \\ ${ }^{3}$ University of Waterloo, Electrical and Computer Engineering Department, Waterloo, Ontario, Canada
}

\begin{abstract}
Anodic nanoporous alumina (NPA) is known to be a low cost material suitable for fabrication of templates for the growth of a variety of nanostructured materials, membranes and sensors. In this work, nanoporous alumina was prepared in $0.4 \mathrm{M}$ oxalic acid by a two-step anodization process. The properties of nanoporous alumina film grown on aluminum foil were studied by atomic force microscopy (AFM), scanning electron microscopy (SEM) and optical microscopy. The microscopy investigations confirm the pore formation in the produced layers and the process of anodization allows consistent fabrication of nanoporous alumina. The effect of anodization process parameters on the size of the nanopores and the distance between them were studied and good agreement with published data was found. Hence a desired diameter of the pores and the distance between of it can be obtained by adjusting the electrolyte and oxidation voltage.
\end{abstract}

Keywords: nanoporous alumina, anodic oxidation, anodization process,pore formation.

PACS number(s): 63.22.Np,82.45.Cc

\section{Introduction}

Nanoporous alumina can be prepared in various acid solutions (oxalic acid $(\mathrm{COOH}) 2$, sulfuric acid H2SO4, orthophosphoric acid H3PO4) $[1,2,3]$. Formation of porous alumina is due to the anodization process of the metal in the solvent electrolytes. When a weak electrolyte, such as boric acid $\mathrm{H} 3 \mathrm{BO} 3$, tartaric acid $\mathrm{C} 4 \mathrm{H} 6 \mathrm{O}$, citric acid $\mathrm{C} 6 \mathrm{H} 8 \mathrm{O} 7$ and so on, is used, the barrier-type alumina layer is formed instead the nanoporous alumina film; the thickness of the barrier-type alumina can be up to $1 \mu \mathrm{m}$ [1]. The basic reaction in the preparation of a porous oxide film is as following:

$$
\begin{gathered}
2 \mathrm{Al}+3 \mathrm{H}_{2} \mathrm{O} \rightarrow \mathrm{Al}_{2} \mathrm{O}_{3}+3 \mathrm{H}_{2} \\
\mathrm{Al}_{2} \mathrm{O}_{3}+6 \mathrm{H}^{+} \rightarrow 2 \mathrm{Al}^{3+}+3 \mathrm{H}_{2} \mathrm{O}
\end{gathered}
$$

First, the barrier layer is formed (1). Then dissolve the barrier layer (2) and porous alumina layer is formed [7]. The structural characteristics of the porous film are affected by the basic parameters of anodizing process. Studying the dependence of structural features of the film on the

\footnotetext{
* Corresponding author: e-mail: kh.a.abdullin@mail.ru
}

parameters of anodizing is thus an important element in the preparation of porous alumina.

Initial studies of structural features of porous alumina are dated back to 19th century [4,7]. In preparation of porous alumina, the focus was on the study of porous structure formation, i.e the dependence of the film structure on the anodization process parameters. Keller reported that an increase in anodization voltage leads to an increase in the diameter of the cell, however has no effect on the pore size [4,5]. Later reports indicated that an increase in anodization voltage causes the pore diameter to increase accompanied by higher current density and gas emission on the surface of electrodes [6]. The pore diameter was found to be proportional to the applied voltage, and the reaction rate was directly related to the current density and increases exponentially with the voltage $[4,5]$.

In this paper, we studied the influence of the main parameters of the anodizing process on the structure of nanoporous alumina. It was determined that at low temperatures $\left(4-5^{\circ} \mathrm{C}\right)$ the anodization process is more stable at high voltages, voltages affect on the pore size and thickness of the NPA film. The novelty of the work is to identify the most suitable parameters for porous alumina films and production nanostructured materials based on it. 


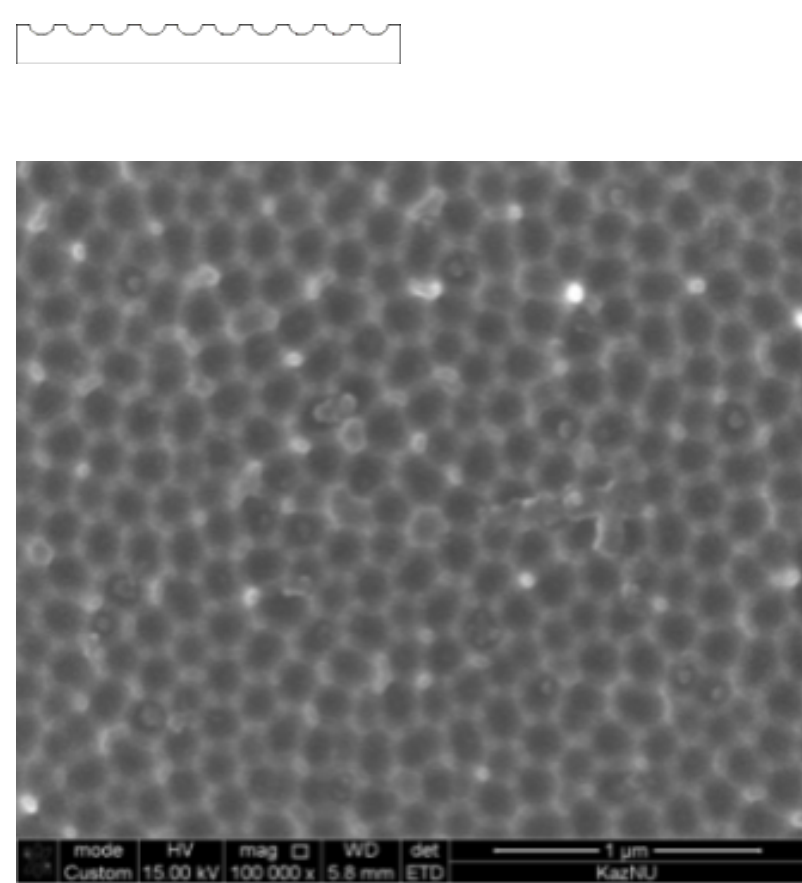

a)
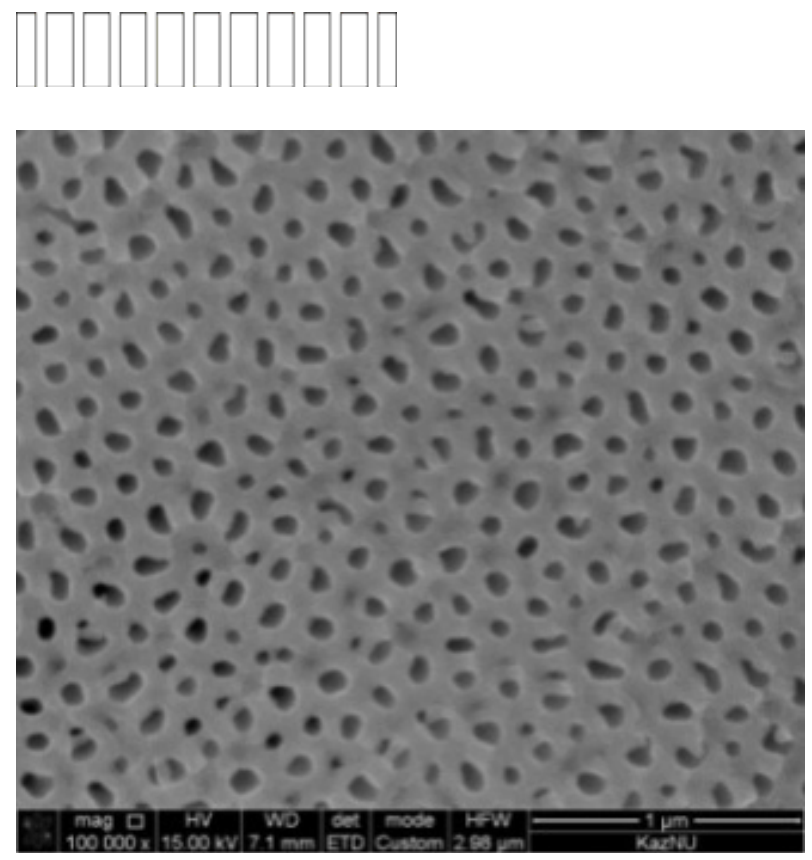

c)

Figure 1 - SEM images of NPA films at different formation stages:

$\mathrm{a}$ - after removal of an oxide layer; $\mathrm{b}-2$ nd step of anodizing; $\mathrm{c}$ - after opening the pores on the back side.
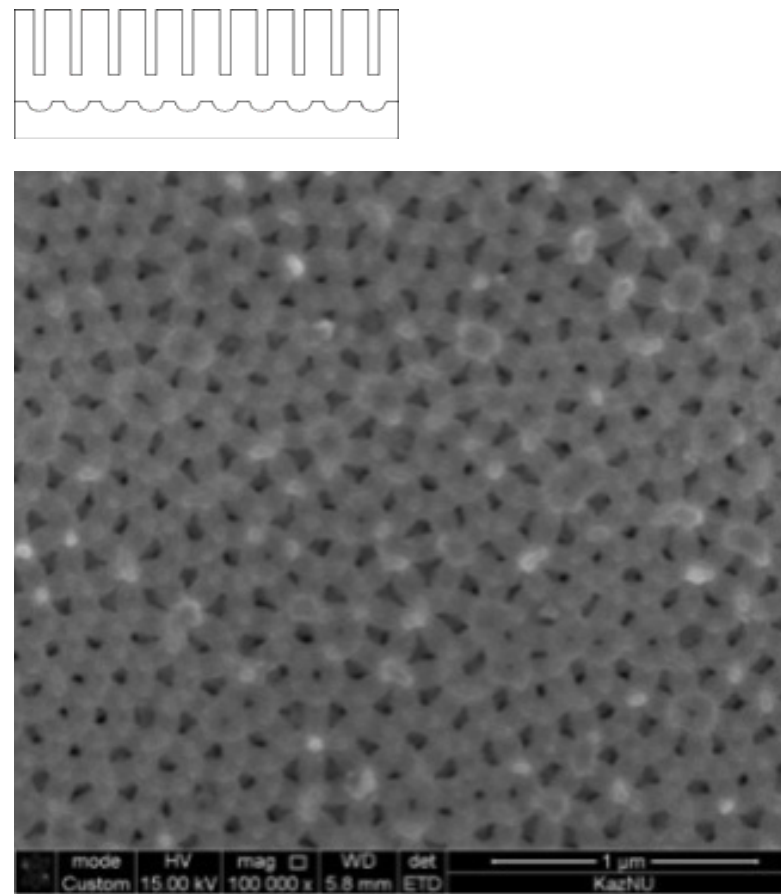

b) 


\section{Experiments}

Figure 1 shows the SEM images of NPA surface at different stages of anodizing process. At first, the surface of high purity aluminum foil $(99.99 \%)$ was polished and cleaned in an ultrasonic bath after thermal annealing at $500{ }^{\circ} \mathrm{C}$ (3 hours). After thermal annealing, oxalic acid $(\mathrm{COOH})_{2}(0.4 \mathrm{M})$ was injected into a custom designed fluoroplastic cell (Figure 2 a) and contacted the exposed aluminum foil over small area of $0.1-0.2 \mathrm{~mm}^{2}$. Thenaluminum foil was anodized under constant voltage conditions (30$100 \mathrm{~V})$. Completion of the anodization wasindicated by a steep drop in the anodization current indicating the formation of a residual alumina barrier layer. After first anodization (1-3 hours), selective dissolution of the formed oxide layer in $\mathrm{H}_{3} \mathrm{PO}_{4} / \mathrm{CrO}_{3} / \mathrm{H}_{2} \mathrm{O}$ solution at of $70-80{ }^{\circ} \mathrm{C}$ was carried out (Figure $1 \mathrm{a}$ ).

Second anodization (Figure 1 b) was done under the same conditions as the first anodization (1 hour). The aluminum substrate was dissolved by a solution of hydrochloric acid and copper sulfate. Then remains of solution were rinsed with deionized water and the pores were open on the back side of NPA film using 5\% phosphoric acid $\left(\mathrm{H}_{3} \mathrm{PO}_{4}\right)$ (Figure $1 \mathrm{c}$ ).

Figure 2,b shows two types of alumina: 1) barrier-type, and 2) porous-type alumina films. They consist of an inner oxide of high purity alumina and an outer oxide layer comprised of alumina which incorporated anions $[5,7]$.

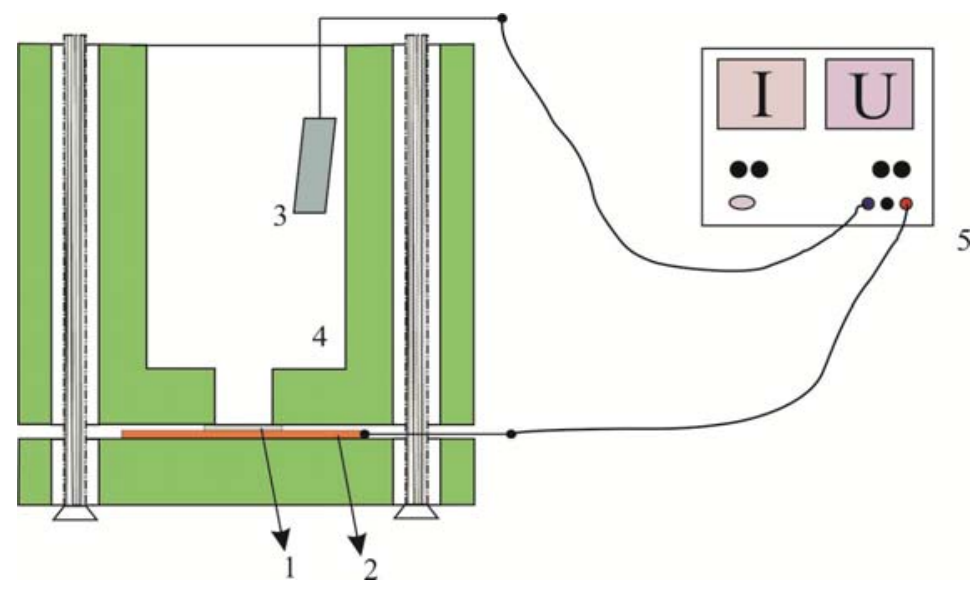

a)

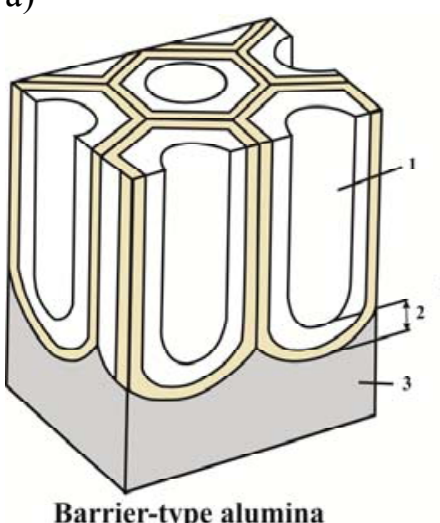

b)

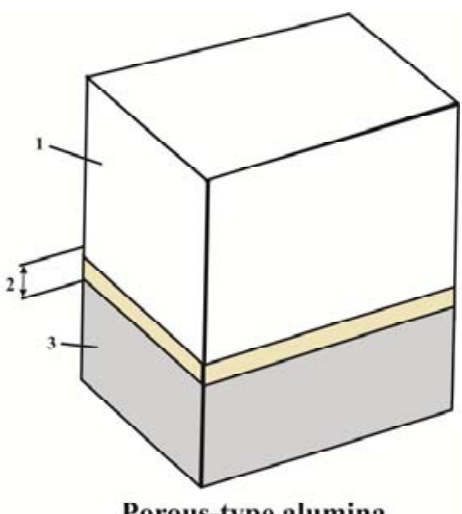

Porous-type alumina

Figure 2 - a) Anodization cell cross-section: 1 - aluminum foil; 2 - copper plate; 3 - tungsten plate; 4 - electrolyte (oxalic acid $\left.(\mathrm{COOH})_{2}(0.4 \mathrm{M})\right) ; 5$ - power source; b) alumina film cross-sections: barrier-type (left image) and porous-type (right image); 1 - outer oxide; 2 - inner oxide; 3 - aluminum. 
When carrying out process of anodizing, the size of given tension, electrolyte temperature, composition, and concentration of electrolytes, and process time affected obtained characteristics of $\mathrm{Al}_{2} \mathrm{O}_{3}$ porous layers, such as pore diameter, thickness of porous and barrier layers.

In particular, linear dependencies exist between the following parameters [8]:

$$
\mathrm{D}_{\mathrm{C}}=-1.7+2.8 \mathrm{U}_{\mathrm{A}},
$$

where $\mathrm{D}_{\mathrm{C}}$ - the period between the pores (nanometer), $\mathrm{U}_{\mathrm{A}}-$ anode tension (B).

$$
\mathrm{nD}_{\mathrm{p}}^{2}=2.6413 \times 10^{-17} \mathrm{j}^{-0.3189} \mathrm{~T}^{6.6632},
$$

where $\mathrm{n}$ - pore number per $1 \mathrm{~cm}^{2}, \mathrm{D}_{\mathrm{p}}$ - pore diameter (nanometer), $\mathrm{j}-$ current density $\left(\mathrm{mA} / \mathrm{cm}^{2}\right), \mathrm{T}$ - electrolyte temperature $(\mathrm{K})$.

Every anodization stage was investigated by optical microscopy using Leica DM 6000 M (Leica), Atomic Force Microscopy (NtegraTherma (NT-MDT)), and Scanning Electronic Microscopy (Quanta 3D 200i (FEI Company)).

\section{Results and discussions}

The formation mechanism of porous alumina consists to the three stages. At first, in anodization process the current density increases to its maximum value (first stage), then slowly decreases (second stage). Finally, a steady current density is set (third stage). This current density depends on the electrolyte properties and on the temperature as well as on the applied potential. Such dependence is observed under different voltages. The higher the voltage of anodization process, the greater the maximum current density. It takes a few minutesto reduce the current density sufficiently. Table 1 and Table 2 show the effect of anodization process voltage on the pore size and thickness of nanoporous alumina. The pore diameter was found to be in the range of $30-40 \mathrm{~nm}$ after anodisation at $30 \mathrm{~V}$, and the diameters of the pores increase from $\sim 80$ up to $\sim 130 \mathrm{~nm}$ with increase in the anodizing voltage from $70 \mathrm{~V}$ up to $100 \mathrm{~V}$ (Table 1). Similar pores were observed on the SEM images (Figure 3). At the same time, increasing of the voltage leads to increasing thickness of NPA film (Table 2).

\begin{tabular}{|c|c|c|c|c|c|}
\hline \multicolumn{5}{|c|}{ PARAMETERS OF ANODIZATION PROCESS } & \multirow{3}{*}{$\begin{array}{c}\text { Interpore } \\
\text { distance }(\mathrm{nm})\end{array}$} \\
\hline Voltage & \multirow{2}{*}{ Electrolyte } & \multirow{2}{*}{$\begin{array}{c}\text { Temperature } \\
\left(\mathrm{T},{ }^{\circ} \mathrm{C}\right)\end{array}$} & \multicolumn{2}{|c|}{ anodization process time } & \\
\hline$(\mathrm{U}, \mathrm{V})$ & & & 1st stage $(\mathrm{t}, \mathrm{min})$ & 2nd stage $(\mathrm{t}, \mathrm{min})$ & \\
\hline 30 & $\begin{array}{c}\text { Oxalic acid }(\mathrm{COOH})_{2} \\
(0.4 \mathrm{M})\end{array}$ & $7-8$ & 180 & 60 & $70-80$ \\
\hline 70 & $\begin{array}{c}\text { Oxalic acid }(\mathrm{COOH})_{2} \\
(0.4 \mathrm{M})\end{array}$ & $7-8$ & 120 & 30 & $170-180$ \\
\hline 100 & $\begin{array}{c}\text { Oxalic acid }(\mathrm{COOH})_{2} \\
(0.4 \mathrm{M})\end{array}$ & $7-8$ & 60 & 15 & $240-260$ \\
\hline
\end{tabular}

Table 1 - Effects of anodization voltage on the pore size of NPA.

\begin{tabular}{|c|c|c|c|c|}
\hline \multicolumn{4}{|c|}{ PARAMETERS OF ANODIZATION PROCESS } & \multirow[b]{2}{*}{$\begin{array}{l}\text { Film thickness } \\
\qquad(\mu \mathrm{m})\end{array}$} \\
\hline $\begin{array}{l}\text { Voltage } \\
(\mathrm{U}, \mathrm{V})\end{array}$ & Electrolyte & $\begin{array}{c}\text { Temperature }(\mathrm{T}, \\
\left.{ }^{\circ} \mathrm{C}\right)\end{array}$ & $\begin{array}{l}\text { anodization process time }(\mathrm{t}, \\
\text { min) }\end{array}$ & \\
\hline 40 & Oxalic acid $(\mathrm{COOH})_{2}(0.4 \mathrm{M})$ & $10-11$ & 180 & $4-5$ \\
\hline 50 & Oxalic acid $(\mathrm{COOH})_{2}(0.4 \mathrm{M})$ & $10-11$ & 180 & $8-9$ \\
\hline 60 & Oxalic acid $(\mathrm{COOH})_{2}(0.4 \mathrm{M})$ & $10-11$ & 180 & 13 \\
\hline 70 & Oxalic acid $(\mathrm{COOH})_{2}(0.4 \mathrm{M})$ & $10-11$ & 180 & 17 \\
\hline 80 & Oxalic acid $(\mathrm{COOH})_{2}(0.4 \mathrm{M})$ & $10-11$ & 180 & 37 \\
\hline 90 & Oxalic acid $(\mathrm{COOH})_{2}(0.4 \mathrm{M})$ & $10-11$ & 180 & 44 \\
\hline 100 & Oxalic acid $(\mathrm{COOH})_{2}(0.4 \mathrm{M})$ & $10-11$ & 120 & 40 \\
\hline
\end{tabular}

Table 2 - Effects of anodization voltage on NPA thickness. 


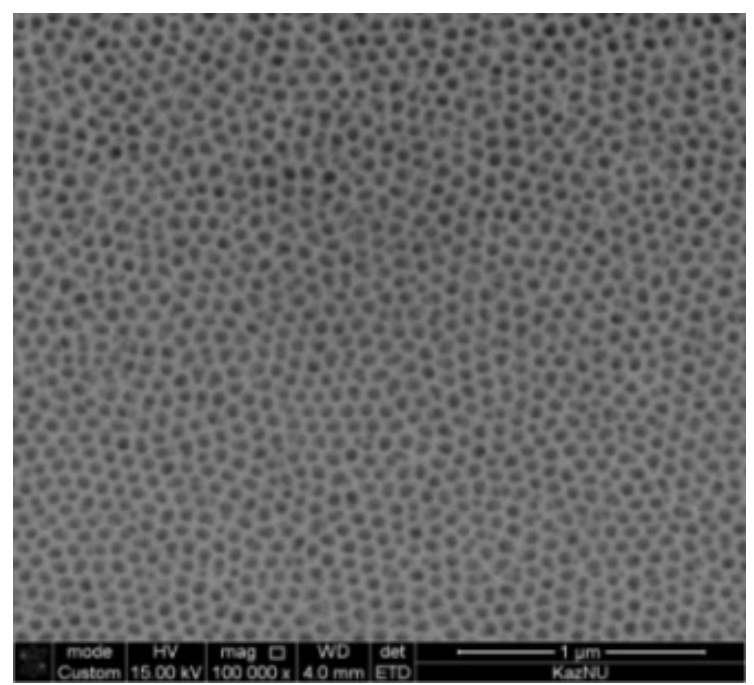

a)

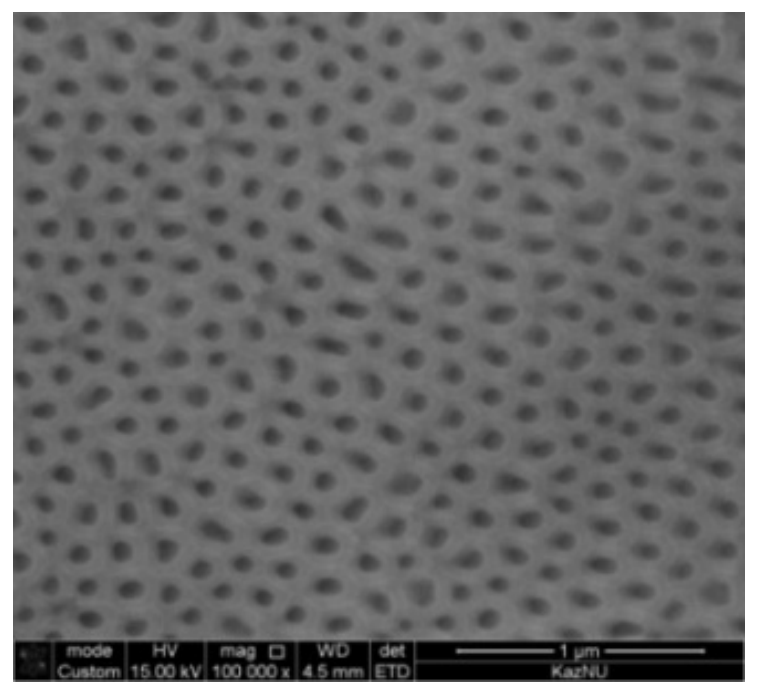

b)

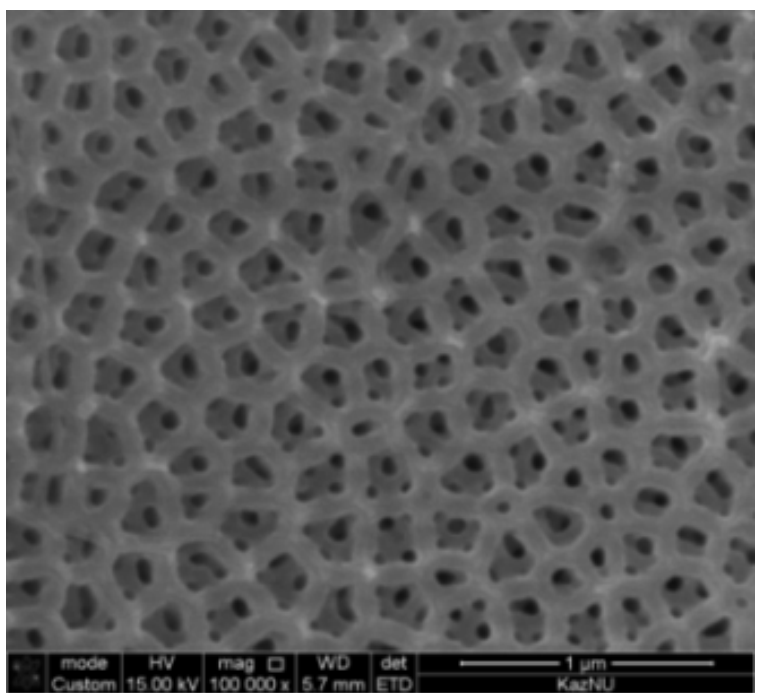

c)

Figure 3 - SEM images of NPA after the second anodization: a) at $U=30 \mathrm{~V}$; b) at $\mathrm{U}=70 \mathrm{~V}$; c) $\mathrm{U}=100 \mathrm{~V}$

Figure 4 shows the distribution of the pore size on the $700 \times 700 \mathrm{~nm}^{2}$ AFM scan. The average pore size of NPA film is $55 \mathrm{~nm}$ (Parameters of anodization: $\mathrm{U}=32,2 \mathrm{~V}, \mathrm{~T}=10^{\circ} \mathrm{C}, \mathrm{t}=60 \mathrm{~min}$ ).

It should be noted that two modes etchingwere observed at the anodizing voltage of $100 \mathrm{~V}$ and they were significantly differ in etching rate, diameters of the pores and interporous distance. Mild anodization mode (Tables 1 and 2) are implemented at low currents and characterized by etching rate of about 0.3 microns per minute and coefficient of proportionality between the interporedistance and the voltage was $\sim 2.5$ $\mathrm{nm} / \mathrm{V}$.In the "hard anodization" mode the etch rate is increased to about 1.2 microns per minute at comparable durations etching and to 8 microns per minute with short $(30-60 \mathrm{sec})$ etching. The pore diameter and interporedistance was considerably lower in the "hard anodization mode" and coefficient of proportionality between the interporedistance and the voltage was $\sim 1.8$ $\mathrm{nm} / \mathrm{V}$.In this mode, the self-ordered nanoporous anodic aluminum oxidelayers can be obtained in a single etching step. 
Figure 5 shows AFM images of NPA on the cross section. The morphology of different samples, as well as structural features on the cross section can be investigated by AFM method. So the AFM is a good solution to study of dielectric materials such as porous alumina.

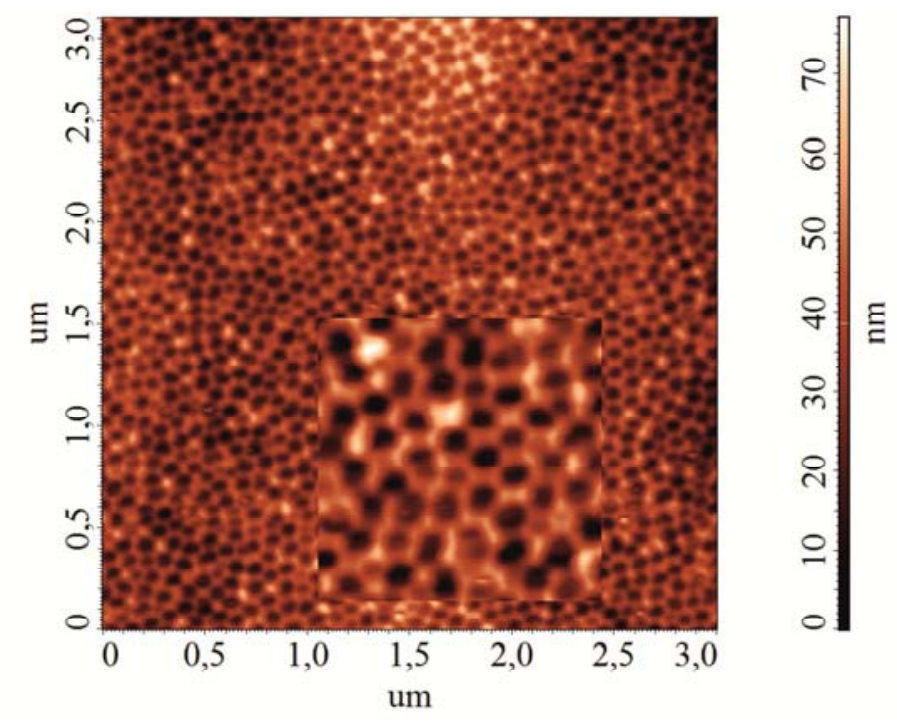

a)

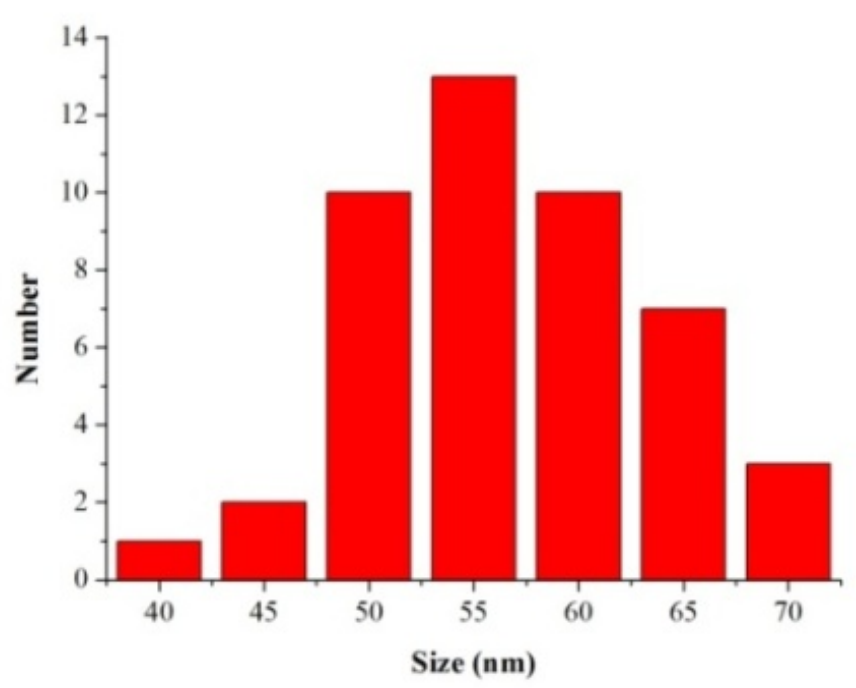

b)

Figure 4 - NPA surface after the second anodization: a) AFM image; b) plot of pore size distribution.

Figure 6 shows AFM images on the cross section with phase images. The phase contrast AFM image is obtained by analysis the phase shift during the scan. The phase shift is highly sensitive to tip-sample force interaction, the phase contrast images contain information related to micromechanical properties of the sample materials. Structure of the pores and $\mathrm{ZnO}$ in the pores are shown in Figure 6. Materials of different natures are different in color. The phase composition of the composite material, bright and dark regions are thought to be associated with the porous alumina (bright) and zinc oxide (dark) phases, respectively. 


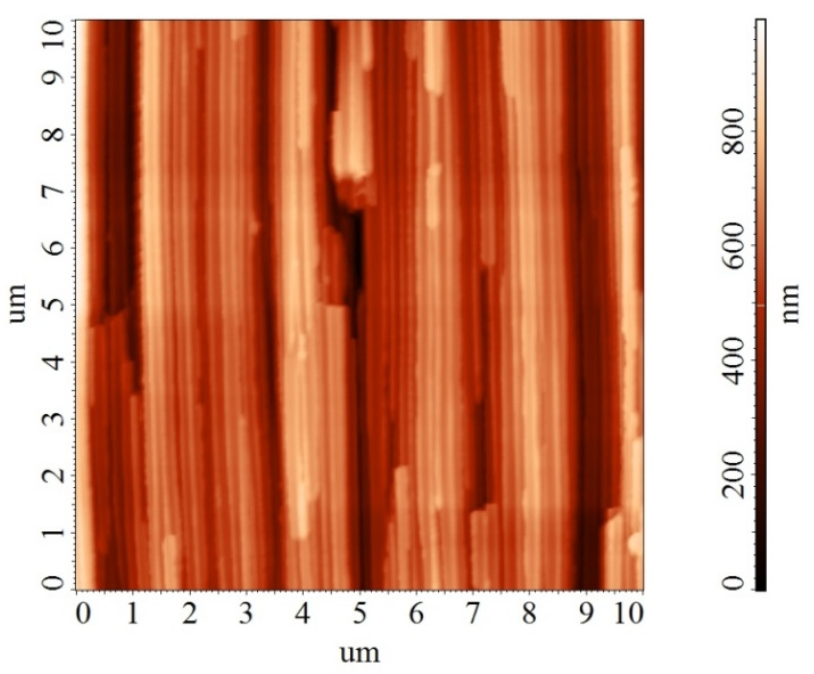

Figure 5 - AFM image of NPA on the cross section.
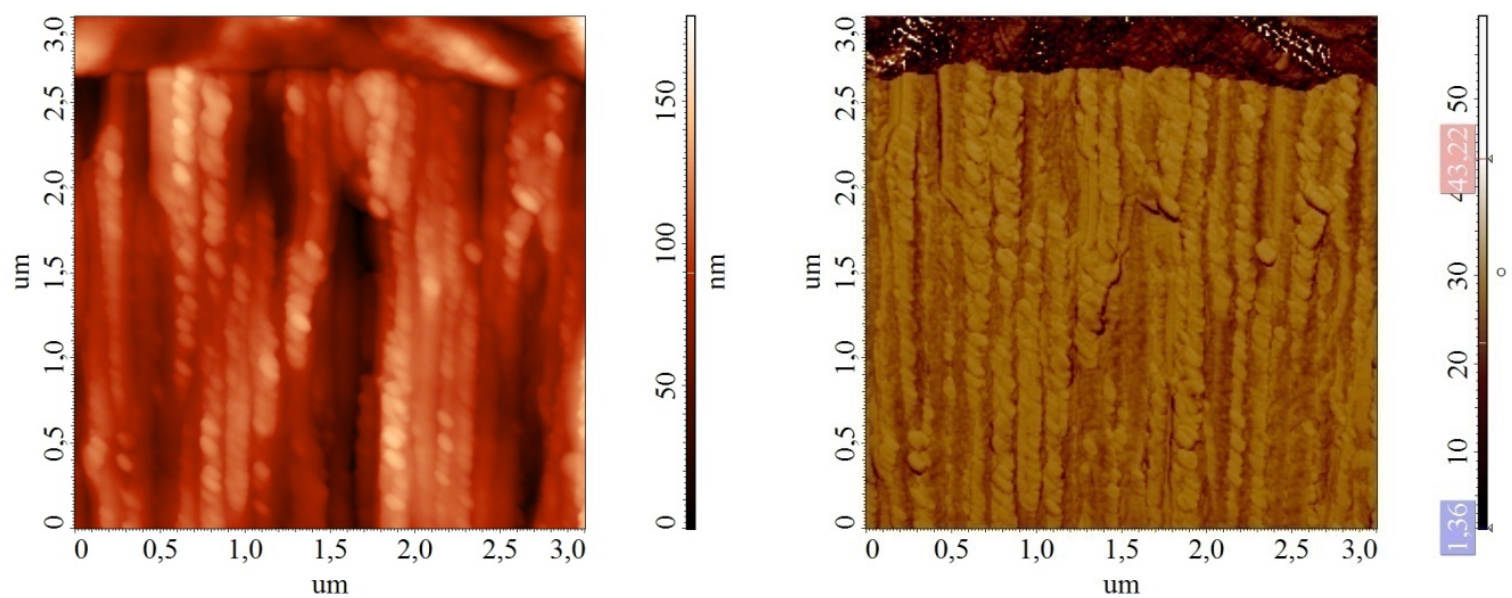

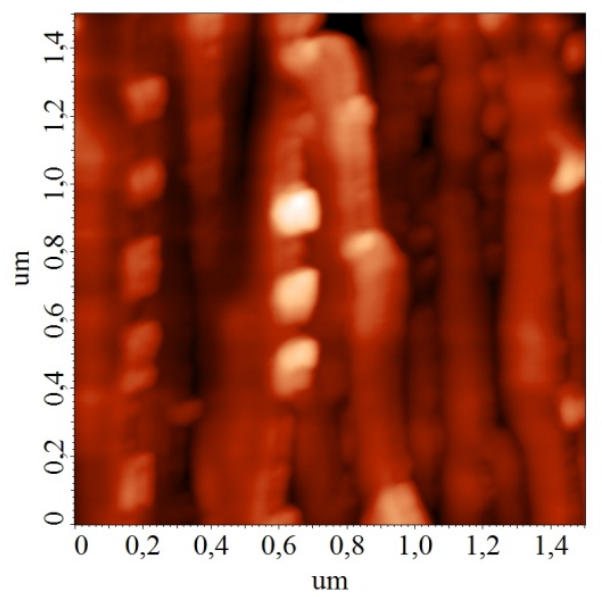

a)

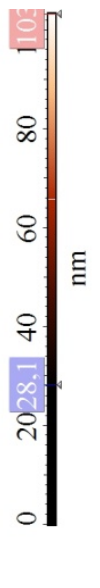

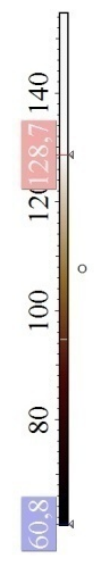

b)

Figure 6 - (a) AFM image of NPA on the cross section $(3 \times 3 \mu \mathrm{m}$ and $1.5 \times 1.5 \mu \mathrm{m})$, (b) phase AFM image $(3 \times 3 \mu \mathrm{m}$ and $1.5 \times 1.5 \mu \mathrm{m})$. 


\section{Conclusion}

These studies of nanoporous anodic aluminum oxide demonstrated that the pore size, the distance between them and the film thickness can be controlled by main parameters of anodization process: the type of electrolyte and its temperature, anodization voltage, and the purity of aluminum foil. Increasing the voltage of anodization process increases the etching rate and pore diameters of NPA film. These porous films can be used as mask templates or nanoreactors to grow various nanostructured materials, also can be used as membranes or test samples for various modern research and analytical devices.

\section{References}

[1] Nielsch K., Choi J., Schwirn K., Wehrspohn R.B., Gösele U.: Self-ordering Regimes of Porous Alumina. The 10\% porosity Rule. Nano Letters 2 (7), $677-680$ (2002).

[2] MengXiangfeng, Wei Guoying, GeHongliang, Yu Yundan, Cao Ying, Horst Dettinger. Anodization for 2024 Al Alloy from Sulfuric-Citric Acid and Anticorrosion Performance of Anodization Films. Int. J. Electrochem. Sci., 8, 10660 - 10671(2013).

[3] RohanAkolkar, UzielLandau, Harry Kuo, Yar-Ming Wang. Modeling of the current distribution in aluminum anodization. Journal of Applied Electrochemistry 34: 807-813 (2004).
[4] F. Keller, M.S. Hunter, and D.L. Robinson. Structural Features of Oxide Coatings on Aluminum. Journal of the Electrochemical Society, 100:411-419 (1953).

[5] Lohrengel, M. M. Mater. Sci. Eng. R11, 243 (1993).

[6] F. Li, L. Zhang, and R.M. Metzger. On the Growth of Highly Ordered Pores in Anodized Aluminum Oxide. Chemistry of Materials, 10, 2470-2480 (1998).

[7] Setoh, S.; Miyata, A. Sci. Pap. Inst. Phys. Chem. Res. (Tokyo). 19, 237 (1932).

[8] Belov A.N., Gavrilov S.A., Shevjakov V.I. Osobennostipoluchenijananostrukturirovannogoanodnog ooksidaaljuminija. Rossijskienanotehnologii, t.1, \#1-2, S.223-227 (2006) 